diagnosis of typlooid at an earlier period than the Widal test. He inoculated rabbits with typhoid cultures and obtained a positive typhoophthalmic reaction within 48 hours.

(IVm. L.)

\section{THE TUBERCULIN SALVE.}

(By E. Moro, Munich Med. Woch., Feb., 1908.)

Moro describes a new method in the liagnosis of tubercnlosis which, if "the favorable account as given by him should be confirmed, the method slould take front rank in point of simplicity and harmlessness. The salve is composed of equal parts of Koch's original tuberculin and of anlydrous lanolin. About 1-10 gram of this ointment is rubbed into the skin of the epigastrium or of the pectoral region for one minute over a surface two inches in diameter. There are three positive reactions which he describes as follows:

1. A mild reaction only shows a few pale red norlules which appear between 24 and 48 hours after the application. This may last several days.

2. A moderate reaction consists in the appearance of a number of bright red nodules, within 24 hours after application, attended witl some itching.

3. The serere reaction is still more rapid. The number and the size of the papules are increased and the eruption has a tendency to extend beyond the seat of the inunction. The papules simply dry and desqumate. No eonditional reaction ever manifests itself.

(Wm. L.)

\title{
OBSTETRICS AND ABDOMINAL SURGERY
}

TREATMENT OF ACUTE MAMMARY ABSCESS.

(Alexander Lyle, MI. D., Ncw York Polyclinic Jourtal, August, 1903.)

The fact that acute mammary abscess can be effectually eured in a period of ten to fourteen days, and the function of the breast restored after that time-in the vast majority of cases-if the proper form of treatment be carried out, appears to have been overlcoked by many members of the profession at the present day. A fissured nipple can usually be discovered as the avenue of infection. Antiseptic dressings, with the constant application of the ice-bag, will, in some cases, prevent suppuration; but should suppuration occur, the breast should be incised at onee.

The incision should be made parallel witl the lacteal ducts, i. e., radiating from the nipple, after the skin has been injected with a one-lalf per cent. cocaine solution. The pus is evacuatel, the carity thoroughly irrigated with a warm saline solution, and the finger introduced to break up all pockets. The sharp curette is now macle use of, and the walls thoroughly curetted. The cavity is again irrigated, after which the finger, wrapped with sterile gauze, is inserted and the walls of the cavity carefully wiped to remove any small particles left by curette. Irrigate again and pack the cavity with sterile gauze for a few moments, in order to dry it. Remove the gauze and apply pure earbolic acid. In small cavitics, cotton wound on an applicator and saturated with carbolic acid may be used to wash down the walls, but in larger cavities it is preferable to pour in a quantity of it, so as to allow it to come in contact with all portions of the cavity. This is neutralized, after a couple of minutes, with pure alcohol. The cavity is now carefully dried, and a small wick of gauze put into the skin incision, not into the abscess cav- 
ity. If the skin incision has been long, the edges of the upper portion may be brought together with suturcs, leaving only a sufficient opening for the necessary drainage. This is now, as nearly as possible, a sterile wound. The plastic lympl has been curctted away, and if the walls can be brought together, an adhesive inflammation will ensue that will promptly obliteratc the cavity and effcct a cure. Here we must rely on compression, and it must be of such a character as will mould itself to the irregularities of the injured breast.

A large sca-spongc bcst answers the rcquiremcnts. This should be flat, two or three inclies thick (when wet) and slightly larger in diameter than the affected breast. The prelininary preparation of the sponge consists in frequent washings to remove sand and shells, and finally in a prolonged washing in a hot two and one-half per cent. solution of carbolic acicl. It is then squeezed as dry as possible, placed hot upon the breast, covered with oiled silk, and lield in place by a firm roller bandage, extending not only about the chest, but also over the opposite shoulder, so as to form a firm support to the breast. $A$ small portion of the sponge is left exposed at the clavical, and the patient instructed to pour in two or three ounces of a hot two and one-half per cent. solution of carbolic acid every four hours. This keeps the sponge moist, and consequently it expands to its limits and a constant equal pressurc is exerted. Be careful to see that the breast is empty and that no milk remains in the ducts before compression is applied. The sponge is clanged daily, thoroughly washed in hot carbolic solution and rcapplied. The gauze wick is removed at the end of twentyfour hours and not rcapplied. In a few instances the above solution may cause some irritation to the skin, in which case its strength can be reducel. The discliarge from the breast will be bloody pus for about two days; it will then change to a seropurulent, and finally to a very light serous, so that at the end of eight to ten days there is no discharge. When the discharge ccases, we know that the cavity is obliterated and the compression can be dispensed with. All that remains is the skin wound, which can be rapidly healed by the application of icthyol ointment.

When the sponge is removed, the milk will return unless there has been very extensive destruction of the gland. (G. C. T.)

\section{THE TREATMENT OF APPENDIX ABSCESS.}

(By Archibald W. Cuff, B. A., M. B., B. C. Cantab., F. R. C. S. Eng. Surgeon to the Royal Infirmary, Sheffield, London Lancet, Aug. S, 1908.)

The presence of pus as a complication of appendicitis is a very serious menace to the life of a paticnt. It is impossible to foretell whether diffuse peritonitis or localized abscess will ensue. Even if the latter should result the risk to the life of the patient is still great, as the abscess may at any time burst into the general peritoneal cavity. Other complications that may arise are toxemia, septic venous thrombosis and pyrmia. The patient's lifc is jeopardized by waiting and convalescence is prolonged. Early opcration with evacuation of pus and primary appendectomy is adrised as soon as possible after diagnosis.

Whilc theoretically in dealing with free pus in the peritoneal cavity there is danger of spreading it to unsoiled intestine, and increase peritonitis and toxic absorption, practically, this area can be avoided by moderate care and caution. It is casier to remove the appendix then than to wait for secondary operation after formation of adhesions in which there may bc great difficulty in identifying the appendix; furthermorc, the patient should be spared the risk of a second operation and anxsthetic if possible. While in many instances there is never again any trouble after merely draining the abscess, Treves has estimated that 17 per 
cent. have recurrence in some form, and 40 per cent. of that number liave been the subject of sinus.

The primary remoral of the appendix adds very little to the gravity of the drainage operation. The wound will close more promptly and the patient is not the subject of an unpleasant sinus or fistula, which may persist for months if the appendis is not removed, leading necessarily to the formation of a weak scar and liability to subsequent hernia.

While some surgeons advise opening these abscesses through the vagina or rectum, this nethod is unsatisfactory and dangerous in some cases. Unsatisfactory because other abscesses may be present, distinct, and remotely situated from the pelric abscess drained. Dangerous on account of pus gravitating up to diaphragm and subphrenic abscess result when pelris is elerated in performing this operation.

Based on the above facts the operative treatment of appendiceal abseess should con form as near as possible to the following proposition:

1. Choose the abclominal route.

2. The incision sliould be placed to allow easicst access to the origin of the trouble.

3. Incision should be large and capable of extension so as to insure easy manipulation and quick operation.

4. Do priniary appendectomy and aroid second operation, if possible.

5. Do as little mutilation as is compatible with thoroughness.

6. Avoid two incisions if one properly placed will answer.the purpose.

7. Drainage tube, both in size and number, should be reduced to a minimum, because tubes arc liable to injure peritoneum and preclispose to intestinal obstruction from adhesions as well as leave a weak scar.

8. Avoid injury to nerve supply and muscular fibers.

Seventy-six pus cases are reported oceurring in the last $31-2$ years, 8 of that number having diffuse peritonitis, the remaining 68 laving abscess of every size and position not necessarily walled off, but more or less limited to appendix region in which the greater part of the boundaries are formed by abdominal parieties and small part by intestines. Of the 8 cases of diffuse peritonitis there was a mortality of 50 per cent-one of that number recovered from peritonitis, but died three weeks later from intractable fecal fistula and slougling wound. (The appendix was not removed at time of operation.) Of the 68 cases of abscess whicl were operated upon linere were but two deaths, a little less than 3 per cent. mortality, as compared to 11 per cent. mortality given by Battle as the conjoint resnlt of the operations at Guy's, St. George and Middlesex Hospitals. Battle records a mortality of 10 per cent. in a serics of 100 cases under his own care.

It is impossible to lay down definite rules when to operate in appendicitis. Undoubtedly the presence of pus calls for inmediate operation, particularly if symptoms do not subside in thirty-six hours pus is probably forming; if forty-eight hours pass without improvement j,115 is nearly always present.

Incision made at outer border riglit rectus. Pack off carefully in every direction and liberate pus; roll to right side, protect edges of wonnd with gauze; mop out thoroughly the fiud and free the appendix: in the ordinary way; be especially careful to bury stump. either in crecum or in its own peritoneum. Use Irainage as necessities of the ease demand. Washing out an abscess cavity should never be done.

After Treatmont.-Place on riglit side, elevate head of bed 9 to 12 inches. Keep elevated until discharge from wound ceases, distension is gone and bowels act satisfactorily. Saline injeetions per rectum, pint every 4 hours until patient is out of the woods. The Murphy and Monyihan continuous rectal infusion is not advocated, as it seems more difficult and less satisfactory than the three or 
four hourly infusions. Nursing with it is more difficult and discomfort of paticnt greater. In ordinary cases bowels opened on third or fourth day. Remove tube third day, dress daily and gradually shorten tube until the wound has healed.

(IV. D. H.)

THE NECESSITY FOR THE REMOVAL OF THE APPENDIX AFTER PERITYPHILITIC ABSCESS.

By William Henry Battie, Surgcon to St. Thomas Hospital. (London Larret, July. II, 1908.)

The trcatment of perityphilitie abseess is most safely carried out in two stages.

First Stage-Evaeuation of pus and drainage.

Second Stage-Removal of appendix.

No patient is safe after abscess formation until the appendix las been removed. Tronble will invariably come sooner or later. The appendix is not obliterated by suppurative process, hut remains subject to gross disease which in 20 ont of 70 cases gives rise to a return of symptoms.

Objections to subsequent removal have heen raised:

1. Operation diffieult and dangerous.

2. That few cases require removal as appendix is claimed to be obliterated by suppurative process.

The surgeon should surmount all difficulties in the interest of his patient. The operation is not dangerous if properly performed. The second objection is incorrect as will be shown in the pathological condition described below:

A. When the symptoms of appendicitis recurred or another abscess formed. Showing signs of recent inflammation, I; ehronic inflammation with scars of old perforation, $\mathrm{I}$; concretion and old perforation, 1 ; kinked, 1 ; kinked and adherent, I; kinked, strictured, with scars of old perforation, 3 ; strictured, 2 ; strictured with retained concretions, I 1 ; very idherent, stricturcd, old perforation, I; uni. versally thickencd, stricture, scars of two perforations, concretions, $\mathbf{r}$.

B. Sinus formation after treatment of abscess. Chronic inflammation with closc adhesions, $\mathrm{I}$; with old perforation, 1 ; recent perforation, $I$; stricture, $I$; stricturc, concretion, old perforation, I; very adhcrent. stricture, old perforation, $\mathrm{I}$.

C. Rcmoval during a later peritonitis, the earlicr abscess trcated elscwhere. Recent perforation, 2; in one with a concretion.

D. F.cmoval when no symptoms lave arisen since the closure of the abseess. Marked clrronic inflammation, 5 ; elronie inflammation with old perforation, 4 ; old perforation, 5: kinked, stricture, coneretion, 1 ; kinked, stricture, perforation, 2 ; strieture, old perforation, 8; stricture, 9; doubled on itself, 1 ; contained thread worm, I.

E. Removal after definite rupture into bowel. Marked ehronic inflammation, 2; with old perforation at tip, I; stricture, I; kinked. stricture, recent perforation, $\mathbf{I}$; concretion, recent perforation, $\mathrm{I}$.

F. Removal during operation for evacuation of pus. Recent inflammation, 2 ; with recent perforation, 3 ; with coneretion, 1 ; clironic infammation, 4 ; stricture, I; with recent perforation, 2; gangrenous ulceration and perforation, 2.

G. Spontaneous rupture of abscess into peritoncum. Stricture, 2; gangrenous perforation with concretion, 2. In one fatal case, appendix long, curls on. itself, acute inflammation with slough.

H. In some fatal cases in which the appendix had not been removed during life. Partial slough, 1 ; slough away with part of caccum, I; chronic inflammation, I; concretion removed at operation.

Finding eoneretion in pus of abscess is no 
sign that the cause of disease has been eliminated. Finding a concretion is a proof of the nature of the abscess but another concretion is just as liable to remain in the appendix.

The appendices following abscesses give fcwer instances of apparent recovery than those folnd at operation for recurrent attacks without suppuration.

The appendix slould be removed whether any syruptoms occur or not. Even when appendix sloughs away, part of base may remain and is a dangerous condition. The in- cision should be made over outer border of rectus muscle; easy to approach and inspect area involved, can isolate thoroughly; permits exploration of any stricture from pelvis to gall bladder; veins are not bruised or torn; muscles are not lacerated or divided; often course is singularly free from suppuration and thrombosis or embolism.

The best time for removal is when abscess has recently closed as adhesions are not so dense and are easily handled. (W. D. H.)

\section{SURGERY}

THE RADICAL TREATMENT OF CARCINONA OF THE BLADDER.

Albert Asliton Berg, Antols of Surgery, September, 1908.

The low perentage of cures in operations on the bladder for carcinoma, are due to the complicated problems the surgeon is required to meet, and the failure to appreciate the full pathology: The radical operative eure of a malignant bladder demands a wide removal of the disensed tissue and of the affected lymplatics and glands. The author quotes Mandlebaum as to the importance of recognizing the primary location of the cancer. either in the prostate, rectum, or uterus; and says, for of what use is it to extirpate a part or the whole of the bladder, if thercby is removed only a secondary deposit, whilc the primary growth in the prostate, uterus or rectum is Icft unmolested? In the light of Dr. Mandlebaum's investigations (Srrgery and Gyncology, $V$ 315, 1907), the author does not doubt that many recurrences afte: radical operation, are due to the fact that an unrecognizcd primary focus existing in the prostate, uterus or rectum was left behind at the time of opcration; and he is convinced that attention to the facts brought out by $\mathrm{Dr}$ Mandlebaum will better our percentage of ultimate cures. Bcsides facts concerning the pathology, the author deals with the two principal problems confronting the operator, viz., how widely to remove the neoplasm, and how best to restore or substitute for the urinary bladder? He quotes freely from Rafin as to the mortality in partial cystectomy, whose tables show 2I plus per cent of prinary mortality; also from Watson, whose views differ as to the performance of partial cystectomy, and who advises lumbar nephrostomy with radical removal of bladder and prostate or other scat of primary infection. Of Watson's 25 collected cases of complete extirpation, II survived, and of these only two were alive and free from recurrence after three years; whcrcas, of Rafin's 96 cases of partial cystcetomy, the $5^{0}$ that survived and could be traced, included five that had safely passed the three-ycar limit without recurrence.

Relative to the question of recurrence, the writer is of the opinion that the dangers thereof are not materially dependent upon whether a complete or partial cystectomy be done, but upon whether all the cancer infected glands and lymphatics are removed with the primary tumor, as well as the prostate rectum or uterus if they be involved.

He differs with Watson relative to the indications for complete cystectomy with lumbar 
nephrostomy, and advises partial cystectomy, with reimplantation of the ureter into the remaining portion of the bladder, when we are dealing with growths limited to a third of the bladder, and especially when their site is on the fundus or the lateral wall. When the cancer is diffusely spread over the greater part of the bladder, and a sufficient portion thereof to form a reservoir cannot be saved, or when there is a bad cystitis which does not yield to therapeutic measures, increasing the dangers of ureteral infection after reimplantation, then complete extirpation is advisable if the patient is otherwise sound. The preliminary operation of lumbar nephrostomy would certainly seem to be indicated when complete excision is done.

The author concludes from his own experience in four cases that one should be able to remove fully one-half of the bladder, without materially interfering with the functions of this organ, and that the removal of a third has no appreciable cffect upon the function of the remaining portion. He concludes his very excelient paper with a description of his technic, and avoids the discussion of the removal of cancerous growths with the cautery or the curette.

Under the title of "A New Technic For Nephropexy," Dr. Alexander FIugh Ferguson gives not only a very vivid description of an entirely new operation for anchoring the kidney, but gives a most valuable list of indications for this operation. He says "Floating Kidney" is no longer a border line disease; it belongs to the field of surgery when-
1. Transitory hydronephrosis, due to kinking or folding of a ureter, and characterized by intermittent renal colic and other less prominent symptons, such as an irregularity in the quantity and quality of the urine voided.

2. Chronic hydronephrosis, with more or less atrophy of kidney tissue following a more or less permanent obstruction to the urinary flow through the ureter. The kidney may now become fixed away from its normal site.

3. Unilateral interstitial nephritis not infrequently is caused by the kidney floating. The classic symptoms and signs are present, with constant aching and occasional colic in the region of the wandering organ.

4. Acute torsion of the ureter, giving rise to great and constant pain, with, of course, enlargement and tenderness of the floating kidney.

5. Acute infection of a hydronephrosis-inflammatory symptoms constitutionally, chill, rapid pulsc, fever, colic, pyuria, etc.

6. Suppression of urine in a floating kidncy with Dietl's crisis bespeaks a condition that should be relieved by operation. The above mentioned conditions give rise to many local and remote disturbances. In addition to abnormal findings in the urine, e. g. albumin, bile, blood, casts, and pus, we often find the patient suffering with painful and frequent micturition; or headache and symptoms of uremia; or gastrointestinal disturbances, dyspepsia, vomiting, abdominal distress, constipation, and even diarrhoes.

(Jounal of the American Medical Associotian, August 15, 1908.) 


\section{DERMATOLOGY}

\section{TREATMENT OF BURNS.}

\section{By L. Renner, in Zcuirabalt fur Chrir,} Lcipsic, July 25, pp. 905-936.

He uses a powder of one part bismuth and two parts kaolin and has obtained good results in 100 cases. It keeps the surface dry, prevents infection, and is easily applied and renewed.

(J. M. K.)

\section{ON THE TRANSMISSION OF SYPH-} ILIS TO THE THIRD GENERATION.

By V. Burgstorf, Ann. de Derm. et de Syph., Jalluary, 1908, p. Is.

The question of hereditary syphilis has been very little understood, although certain authors affirmed the possibility of transmission, not only to the second, but also' to the third, and even to the fourth generation. A. Fournier called the general attention to the subject in I8gr.

Basing his opinion partly upon his own experience and partly upon the observation of Boeck, Atkinson, and others, Fournier, with Lannelongue and Besnier, affirms that syplilis can be transmitted to the children by hereditary syphilitics.

When we consider the works, the authors arrange themselves into two classes, as $\mathrm{A}$. Fournier, Lenonier Lannelongue, Boeck, E. Fournier, Jullien, Troisfontaines, Hallopeau, Pospieloff, Generopitomtzeft and Strzeminsky believe that syphilis can be transnitted to the third generation, while others, as Finger, Hutchinson, Pellizari, Aubry and in particular Tarnovsky do not believe that the real disease cannot be transmitted to the third generation.

In spite of these opposite opinions the majority of authors admit that individuals oit the third generation may bear anatomical or functional dystrophies, due to hereditary syphilis of their parents. The subject must be settled upon observations, and as they are very rare the following case 15 reportad in detail by the writer.

Taking interstitial keratitis as the test ef the presence of hereditary syplilis, Burgsicorf has made a minute cxamination of a casc in which a little girl, age five jears, was the subject of interstitial keratitis, - poor nutrition, loss of hair and generally backward develcpment. The father was found to be a corgenital sypliilitic with numerous symptoms of that condition. Acquired syphilis coultl be excluded in the mother and the father and in! the child itself and other possible causes of interstitial keratitis could also be regardel as non-existent. Treatment on antispecific lines resulted in rapid improvement of these conditions in the child. Cases well authenticated of the transuission of syphilis to the thrre? generation, the possibility of 'which is widely disputed, are sufficiently rare to make this experience worth study. (J. M. K.)

\section{NOTE OF THE COMPARATIVE IN- FLUENCE OF THE PARENTS IN HEREDITARY SYPHILIS.}

(Aun. Dem.et.de Syph., by Carle, Feb., OS, p. 93.)

The greater certainty of the eontamination with syphilis when the mother is infected than when the father alone is syphilitic has been energetically supported by numerous writers; and Carle adduces three well narrated cases of healthy offspring resulting from the mar-: riage of men suffering from syphilis in the early secondlary period with women who renained uninfected, the clildren being born thirteen montlhs, eighteen months and nine nontlis after the appearance of the cliange in the father. In all three cases active treatment of the fatler had been undertaken but no treatment of the mother. The children resulting from the union were observed up to the age of one and a half to two years and showed no signs of syphilis. (J. M. K.) 